\title{
A Rare Cause of Ischemic Stroke in Young Age: Infective Endocarditis
}

\author{
Genç Yaşta İskemik Inmenin Nadir Bir Nedeni: Infektif Endokardit
}

\author{
Oğuz Urgan, Serkan Emre Eroğlu, Ömer Faruk Çelik, Özge Ecmel Onur, Arzu Denizbaşı
}

Department of Emergency, Marmara University Pendik Training and Research Hospital, İstanbul, Turkey

\section{ABSTRACT}

Introduction: If untreated, infective endocarditis is virtually always a fatal disease. Fever, cardiac soufflé, and nonspecific symptoms, such as myalgia and fatigue, are common. Here, we present a patient with the last diagnosis of infective endocarditis whose pre-diagnosis was meningitis and who developed stroke during the follow-up.

Case Report: A 19-year-old male presented with a complaint of clouded consciousness and hyperthermia that he had experienced for 10 days. He was known to have no systemic disease. No obvious respiratory tract, genitourinary tract, gastrointestinal tract, or skin lesions were observed. Also, there was no neck stiffness on physical examination. He developed left hemiparesia (4/5) during the follow-up of the meningitis, and using cranial magnetic resonance, infarcts were found in the right MCA territories. After all, infective endocarditis was found as the origin of his complaints.

Conclusion: This case report also emphasizes that we should not forget infective endocarditis in the etiology of systemic embolisms, especially in young patients.

Keywords: Endocarditis, embolism, stroke

Received: 05.11.2012 Accepted: 09.01.2013

\section{ÖZET}

Giriş: Tedavi edilmediğinde infektif endokardit neredeyse her zaman ölümcül hastalıktır. Ateş, kardiyak üfürüm ve myalji, halsizlik gibi nonspesifik semptomlar sıktır. Burada, ön tanısı menenjit olan ve takibi sırasında inme gelişen infektif endokardit son tanılı bir hasta sunulmaktadır.

Olgu Sunumu: On dokuz yaşında erkek hasta 10 gündür devam eden yüksek ateş ve bilinç kapalılığı nedeniyle başvurdu. Sistemik hastalığa sahip olmadığı bilinmekteydi. Solunum, genitoüriner, gastrointestinal yolda ya da deride belirgin lezyonlara rastlanmadı. Yine, fizik muayenede ense sertliği de yoktu. Menenjit açısından takip edildiği sırada hastada sol hemiparezi (4/5) gelişti ve kraniyal manyetik görüntüleme ile sağ MCA bölgesinde infarkt saptandı. Neticede hastanın şikayetlerinin kaynağının infektif endokardit olduğu tespit edildi.

Sonuç: Bu vaka sunumu, özellikle de genç hastalardaki sistemik embolilerin etyolojisinde infektif endokarditin hatırlanması gerektiğini vurgulamaktadır.

Anahtar Kelimeler: Endokardit, emboli, inme

Geliş Tarihi: 05.11.2012 Kabul Tarihi: 09.01.2013

\section{Giriş}

Infektif endokardit (IE), çoğunlukla bakterilerle gelişen, kalp kapaklarının, konjenital kardiyovasküler lezyonların, prostetik kapak veya diğer prostetik materyalin tutulumuyla seyreden bir infeksiyon hastalığıdır. Tanı ve tedavi alanında yaşanan önemli gelişmelere rağmen prognozunun kötü ve mortalitesinin yüksek olması nedeniyle ciddiyetini ve güncelliğini hâlâ korumaktadır. Embolik olaylar, IE'li olgularda yaygın ve yaşamı tehdit eden komplikasyonlardır ve diğer hastalıkları ve patolojik durumları taklit edebildiğinden tanıda zorluğa neden olabilir $(1,2)$. Kalp kapak anomalisi olanlar, intravenöz ilaç kullananlar, kapak sklerozu olan yaşlı hastalar, protez kapağı olan hastalar ve diyaliz hastalarında en sık etken olan Streptococcus viridans genellikle subakut endokardite yol açarken, normal kapaklarda Stafilococcus aureus (S. aureus) etken olup akut endokardite neden olabilmektedir $(3,4)$.

Bu sunumda, bilinç bulanıklığı şikayeti ile acil servisimize getirilen 19 yaşında erkek hastaya iskemik inme tanısı konulmuş olduğu ve inmenin etyolojisi araştııılığında ise nasıl infektif endokardit tespit edildiği anlatılıı̧ısı. Yine, acil hekimlerinin genç hastalarda iskemik inme tespit ettiklerinde ayıııcı tanıda infektif endokardit tanısını da düşünmeleri gerektiği literatür eşliğinde tartışıııştır. 


\section{Olgu Sunumu}

19 yaşında erkek hasta bilinç bulanıklığı sebebiyle acil servise getirildi. Hastanın öyküsünden 10 gün önce ateş sebebiyle bir hekim tarafından değerlendirildiği ve üst solunum yolu enfeksiyon tanısıyla adı öğrenilemeyen bir antibiyotik kullandığı öğrenildi. Sonraki günlerde, hastanın devam eden ateş sebebiyle başka bir hekim tarafından tekrar değerlendirildiği ve reçetesinin değiştirildiği de öğrenildi. Özgeçmişinde özellik olmayan hasta bilinç bulanıklığı başlaması üzerine acil servisimize getirildi.

Fizik muayenesinde genel durumu kötü, nörolojik muayenede Glasgow Koma Skalası (GKS) skoru $14\left(\mathrm{E}_{4} \mathrm{M}_{6} \mathrm{~V}_{4}\right)$ olarak değerlendirildi. 4 ekstremitesi spontan hareketli ve 5/5 kas gücünde, pupiller izokorik, direkt ve indirekt ışık refleksi normal idi. Hastanın bilincinin konfüze olması nedeniyle yürümesi değerlendirilemedi. Bilateral babinski refleksi fleksör yanıtlı idi. Arada anlamsız konuşmaları mevcuttu. Hastanın ateş'i $37^{\circ} \mathrm{C}$, arteryel kan basıncı 130/78 mmHg, oskültasyonunda kalp sesleri ritmik, kalp tepe atımı 100/dk, ek ses yada üfürüm duyulmamakta idi. Solunum sayısı 20/dk idi. Solunum sistemi muayenesinde akciğer sesleri doğaldı, ral ya da ronküs yoktu. Ense sertliği olmayan hastanın diğer sistem muayeneleri de normaldi.

Laboratuar incelemelerinde; EKG' de sinüs ritmi ve normal sınırlarda QRS genişliği mevcuttu. Başvurudaki AKG incelemesinde $\mathrm{pH}: 7,41$, PaCO2: 36,5 mmHg, PaO2: 65,8 mmHg, SaO2: \%93,5, HCO3: 23,1 $\mathrm{mmol} / \mathrm{L}, \mathrm{BE}:-0,5 \mathrm{mmol} / \mathrm{L}$ idi. Tam kan sayımında ve biyokimyasal analizlerde lökosit sayısı 21600/mm³ ve CRP değerinin 303,6 mg/l olması dışında dikkate değer bir patolojik bulguya rastlanmadı. Kan ve idrar kültürleri alındı. Ateş ve bilinç kaybı olup, ense sertliği olmayan hastanın bilgisayarlı beyin tomografisi (BBT) görüntülemesinde Özellik yoktu. Lomber ponksiyon' da (LP); açılış basıncı yüksek, BOS incelemesinde WBC: 100/mm³, glukoz: 74 md/dl (Eş zamanlı kan şekeri düzeyi 120 mg/dl), BOS proteini 23 mg/dl olarak saptanmış idi.

Hastanın gelişini takip eden 1. saatin sonunda üst ve alt ekstremite hareketlerinde gerileme olduğu fark edildi (4/5 kas gücü). Çekilen beyin difüzyon manyetik rezonans görüntülemede (Resim 1, 2), sağ MCA (middle cerebral artery)' in beslediği bölge olan sağ parietal lobda, bazal ganglionları da içine alan geniş bir alanda akut iskemik enfarkt alanı saptandı. İskemik inme etyolojisini araştırmak amacı ile ekokardiyografi (EKO) yapıldı. EKO' da mitral kapak üzerinde $1 \times 3 \mathrm{~cm}$ çaplı vegetasyonlar saptanması üzerine hasta infektif endokardit tanısı ile koroner yoğun bakıma yatırıldı.

Bu ünitede takip altında iken sonuçlanan anaerob kan kültür örneklerinin dördünde de direkt incelemelerde gram pozitif koklar olduğu ve metisiline hassas S. aureus üremeleri olduğu öğrenildi. Başlangıçta Gentamisin 3 x 80 mg ve Seftriakson sodium 2x1 gr intravenöz uygulama ile başlanmıştır. Tedavisine daha sonra Daptomisin 1×420 mg ve sonrasında ise Moxifloxacin 1x400 mg intravenöz formları da eklenildiği öğrenilen hastaya ayrıca beyindeki iskemik alanlar ve çevresindeki ödemi nedeni ile enoksaparin sodyum 1x40 miligram ve mannitol \% 20'lik formundan 6×150 mg başlandığı öğrenildi. Koroner yoğun bakımda 17 günlük yatış ve takibi ardından hastanın kardiovasküler cerrahi yoğun bakıma nakledildiği ve burada yapılan mitral kapak replasmanı operasyonu sonrasında 20 günlük yatışı ardından servis şartlarında takip edilmeye başlandığı ve genel durumunun iyi olduğu öğrenildi.

\section{Tartışma}

Infektif endokardit, toplumda 1,9 - 6,2/100000 oranında görülen, kalbin endokard tabakasının enfeksiyonudur ve etken bakteri, virus veya mantarlar olabilir $(1,4)$. Son otuz yılda IE'den ölüm oranları azalmakla birlikte uygun tedaviye rağmen oran \%20-25'dir. IE'li hastalardaki bu yüksek mortalite sıklığı embolik olaylar sonucu meydana

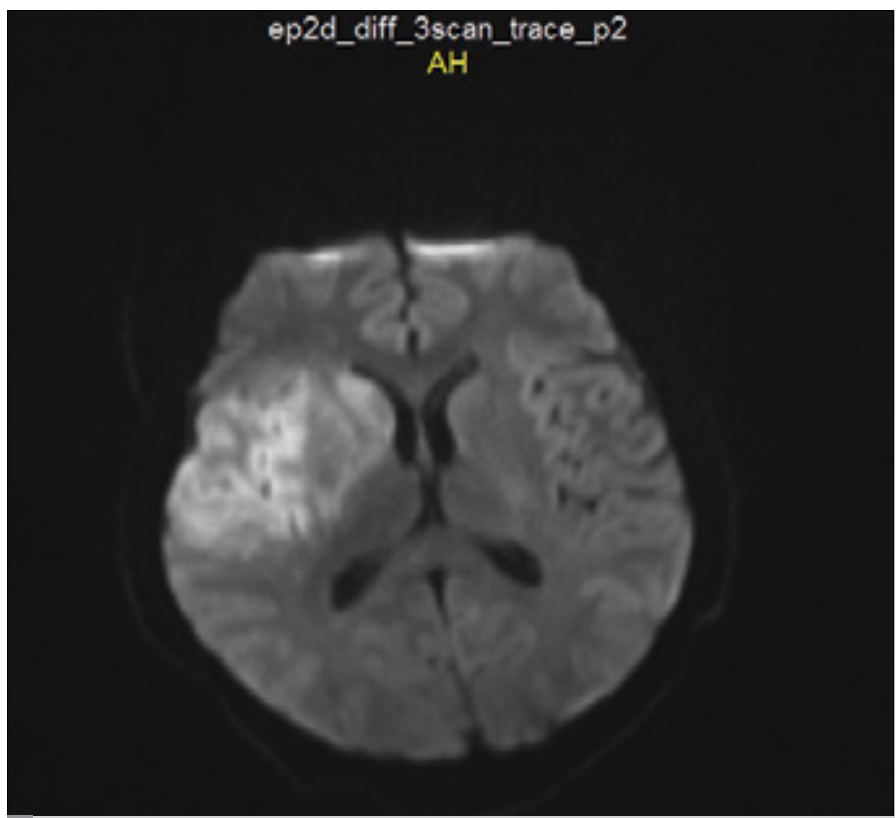

Resim 1. Beyin Diffüzyon MR' da sağ parietal lobda iskemik alan

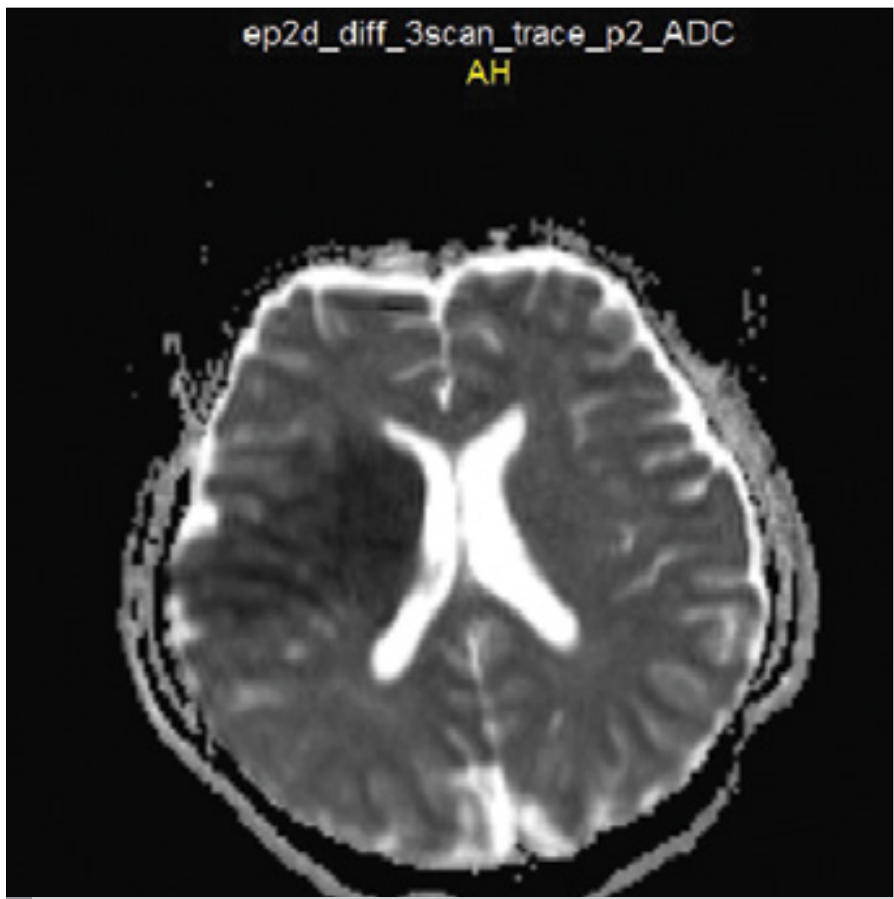

Resim 2. Beyin Diffüzyon MR' da sağ parietal lobda iskemik alan 
gelmektedir. Olguların \%20-43' ünde ortaya çıkan septik emboliler, en sık kalp dışı organlar olmak üzere, \%60 oranında santral sinir sistemine olmaktadır $(5,6)$. Önceden var olan kalp hastalığı, bakteriyemi oluşumu ve enfektif endokarditin ortaya çıkışı arasındaki bağlantı ilk kez 1923 yılında fark edilmiştir (5). Bakteriyemiler yalnızca diş çekimi, tonsillektomi ve bronkoskopi gibi büyük girişimlerden sonra değil diş fırçalarken veya sakız çiğnerken de oluşmaktadır. Özellikle üst solunum yolu enfeksiyonları esnasında kısa süreli ama belirgin bakteriyemiler sıklıkla oluşabilmektedir (6).

Olgumuzda kalp hastalığı veya cerrahi girişim öyküsü olmayıp bakteriyeminin nedeni, kısıtlı klinik bilgi nedeni ile yeterince aydınlatılamamıştır. Ancak olgunun ilk başvuru anındaki ateş, halsizlik gibi şikayetleri ve semptomatik tedavi başlanması muhtemel bir üst solunum yolu enfeksiyonunu düşündürmektedir. Doğal kapak endokarditlerinde kapak ve kapak çevresini içerecek şekilde lokal veya septik vejetasyonların embolisi ve septisemiye bağlı kalp dışı komplikasyonlarına sık rastlanır. Bizim olgumuzda da subfebril ateş, taşikardi, takipneik solunum, lökositoz ve septik görünüm mevcut idi. Sağ kalp endokarditi pulmoner arter embolisi, pulmoner infarkt, pnömoni ve akciğer apsesi ile komplike olabilirken; sol kalp endokarditi beyin, kalp, böbrek, dalak, barsak infarktları ve apseleri ile giden sistemik emboliler ile komplike olabilir (7). Olgumuzda EKO ile mitral kapakta posterior yüzde kapak boyunca uzanan ekodens 1x3 cm çaplı hareketli vegetasyonlar ve beyinde iskemik infarkt alanı saptanmış ve sol kalp endokarditi düşünülmüştür.

Ekstrakardiyak komplikasyonlar içinde ilk sırada yer alan embolik olaylar \%22-43 gibi yüksek oranda görülmektedir. Emboli olduğunda serebral belirtiler diğer belirtilere göre daha çok klinik bulgu vermektedir. Birçok çalışmada beyin, böbrek, dalak ve koroner arterler gibi organ tutulumlarının çok yaygın olduğu ve en sık embolinin santral sinir sistemine olduğu bildirilmiştir (7-9). Bizim olgumuzda da sol kalp endokarditine bağlı, menenjit kliniği veren serebral emboli öne çıkmıştır. Stafilokoklara bağlı IE, tüm IE olgularının 1/3' ünü oluşturan şiddetli ve hayatı tehdit eden bir enfeksiyondur. Genellikle sol kapakları tutar (9). Nitekim bizim olgumuzda da kan kültür örneklerinde gram pozitif koklar olduğu görülmüş ve metisiline hassas S. aureus üremeleri olmuştur.

\section{Sonuç}

İnfektif endokardit günümüzde giderek daha sık görülmeye başlayan, mortalitesi yüksek bir hastalıktır. Bu hastalar, infektif endokardite özgü klinik bulguları göstermeden önce sistemik emboli komplikasyonları ile karşımıza çıkabilmektedir. Özellikle genç hastalarda sistemik inme görülmesi oldukça nadir bir durumdur. İnfektif endokarditin iskemik inme yapabileceği bilinen bir durumdur. Olgumuz ve onun tanısal süreci bizlere acil pratiğimiz sırasında tarafımıza gelen iskemik inmesi saptanan genç hastalarda ilk olarak aklımıza iE gelmesi gerektiğini bir kez daha göstermiştir.

Hasta Onamı: Hasta onamı bu çalışmaya katılan hastadan alınmıştır.

Hakem Değerlendirmesi: Dış bağımsız.
Yazar Katkıları: Fikir - O.U., S.E.E.; Tasarım - O.U., S.E.E.; Denetleme S.E.E., Ö.E.O.; Kaynaklar - Ö.F.Ç., A.D.; Malzemeler - Ö.F.Ç., Ö.E.O.; Veri toplanması ve/veya işlemesi - Ö.F.Ç., O.U.; Analiz ve/veya yorum - S.E.E., A.D.; Literatür taraması - O.U., A.D.; Yazıyı yazan - O.U., S.E.E.; Eleştirel İnceleme - S.E.E., Ö.E.O.

Çıkar Çatışması: Yazarlar çıkar çatışması bildirmemişlerdir.

Finansal Destek: Yazarlar bu çalışma için finansal destek almadıklarını beyan etmişlerdir.

Informed Consent: Written informed consent was obtained from patients who participated in this case.

Peer-review: Externally peer-reviewed.

Author Contributions: Concept - O.U., S.E.E.; Design - O.U., S.E.E.; Supervision - S.E.E., Ö.E.O.; Funding - Ö.F.Ç., A.D.; Materials - Ö.F.Ç., Ö.E.O.; Data Collection and/or Processing - Ö.F.Ç., O.U.; Analysis and/or Interpretation - S.E.E., A.D.; Literature Review - O.U., A.D.; Writing - O.U., S.E.E.; Critical Review - S.E.E., Ö.E.O.

Conflict of Interest: No conflict of interest was declared by the authors.

Financial Disclosure: The authors declared that this study has received no financial support.

\section{Kaynaklar}

1. Mylonakis E, Calderwood SB. Infective endocarditis in adults. N Engl J Med 2001; 345: 1318-30. [CrossRef]

2. Homma S, Grahame-Clarke C. Toward reducing embolic complications from endocarditis. J Am Coll Cardiol 2003; 42: 781-3. [CrossRef]

3. Steckelberg JM, Murphy JG, Ballard D, Bailey K, Tajik AJ, Taliercio CP, et. al. Emboli in infective endocarditis: the prognostic value of echocardiography. Ann Intern Med 1991; 114: 635-40. [CrossRef]

4. Nissen $\mathrm{H}$, Nielsen PF, Frederiksen M, Helleberg C, Nielsen JS. Native valve infective endocarditis in the general population: a 10-year survey of the clinical picture during the 1980s. Eur Heart J 1992; 13: 872-7.

5. Berlin JA, Abrutyn E, Strom BL, Kinman JL, Levison ME, Korzeniowski, et. al. Incidence of infective endocarditis in the Delaware Valley, 19881990. Am J Cardiol 1995; 76: 933-6. [CrossRef]

6. Hart GH, Foster JW, Luther MF, Kanter MC. Stroke in infective endocarditis. Stroke 1990; 21: 695-700. [CrossRef]

7. Kanemitsu S, Tanabe S, Ohue K, Miyagawa H, Miyake Y, Okabe M, et Al. Aortic valve destruction and pseudoaneurysm of the sinus of valsalva associated with infective endocarditis. Ann Thorac Cardiovasc Surg 2010; 16: 142-4

8. Heiro M, Nikoskelainen J, Engblom E, Kotilainen E, Marttila R, Kotilainen P. Neurologic manifestations of infective endocarditis: a 17-year experience in a teaching hospital in Finland. Arch Intern Med 2000; 160 2781-7. [CrossRef]

9. Watanakunakorn C, Burket T. Infective endocarditis at a large community teaching hospital 1980-1990. A review of 210 episodes. Medicine 1993; 72: 90-102. [CrossRef] 